Environmental Hazards, 2015 Vol. 14, No. 2, 156-186, http://dx.doi.org/10.1080/17477891.2015.1028018

\title{
Mapping social vulnerability to flood hazard in Norfolk, England
}

\author{
K. Garbutt ${ }^{\mathrm{a}}$, C. Ellul ${ }^{\mathrm{b}}$ and T. Fujiyama ${ }^{\mathrm{b}}$ \\ ${ }^{a}$ Centre for Urban Sustainability and Resilience, Department of Civil, Environmental and \\ Geomatic Engineering, University College London, Chadwick Building, Gower Street, London \\ WC1E 6BT, UK; ' ${ }^{b}$ Department of Civil, Environmental and Geomatic Engineering, University \\ College London, Chadwick Building, Gower Street, London WC1E 6BT, UK \\ *Corresponding author. Email: k.garbutt.12@ucl.ac.uk
}

\begin{abstract}
In this paper, we present a method to assess social vulnerability through the creation of an Open Source Vulnerability Index (OS-VI). The OS-VI provides context to environmental hazards and allows NGOs and local agencies to better tailor services and provide targeted preemptive vulnerability reduction and resilience-building programmes. A deductive indicator- based approach is utilised to incorporate a wide range of vulnerability indicators known to influence vulnerability. Unlike many vulnerability indices, the OS-VI incorporates flood risk as well as the loss of capabilities and the importance of key services (health facilities and food stores) through the measurement of accessibility when determining an area's level of social vulnerability. The index was developed using open-source mapping and analysis software and is composed completely of open-source data from national data sets. The OS- VI was designed at the national level, with data for all proxy indicators available across the entirety of England and Wales. For this paper, a case study is presented concerned with one English county, Norfolk.
\end{abstract}

\section{Highlights}

- We produce an open-source vulnerability index.

- Accessibility to health care found to be severely affected by flooding.

- High vulnerability areas found to be disproportionately impacted by flooding.

- Urban extent of an area found to increase its level of vulnerability.

- Flood affected areas more likely to be composed of elderly, sick and poor.

Keywords: vulnerability; floods; hazards; mapping; GIS; open source 


\section{Introduction}

Flooding is a significant concern for much of the UK and is recognised as a primary threat by most local councils, with coastal flooding in particular considered one of the highest priority risks across nearly all counties (Cabinet Office, 2013). The UK has a lengthy history of flooding, from the 1953 East Coast storm surge that killed 307 people to the series of floods that affected much of the country throughout 2012,2013 and 2014 and that caused in excess of $£ 1$ billion damage and led to the death of 26 people. Flooding, as with other hazards, can negatively influence location-specific vulnerability as well as the existing sociocultural and response and recovery mechanisms (Wamsler, 2014) by, for example, changing hazard patterns, increasing the number of vulnerable people or amplifying the loss of urban fabric and assets (Wamsler, 2014). It is widely accepted that social, economic and political patterns exist within society that result in some groups of people living with an amplified state of vulnerability (Enarson, 2007; Morrow, 1999). Socially vulnerable populations are often restricted in their ability to respond - often due to increased likelihood of health problems (Marmot, 2005) or constrained economic support (Morrow, 1999) - and more often than not, lack access to critical resources during disaster events (Halden, Jones, \& Wixey, 2005; Morrow, 2008). This often augments the way in which individuals and their wider communities are affected by environmental hazards as well as how they respond and recover.

A greater understanding of the spatio-temporal variances in vulnerability and knowledge of where those viewed as more vulnerable are concentrated within communities, as well as the wider socio-economic circumstances of those communities, are key to understanding a population's level of resilience to environmental hazards (Cutter \& Emrich, 2006) and improving response service capability (Nelson, Lurie, Wasserman, Zakowski, \& Leuschner, 2007). In order to provide practical identification and assessment of social vulnerability, the many influencing factors must be assigned measureable numeric indicators (Atteslander et al., 2008).

As identified by the United Nations Expert Working Group on 'Measuring Vulnerability', the only expert approach to identifying socially vulnerable populations is the production of a vulnerability index: an aggregated or composite measurement of selected proxy indicators of vulnerability, be it mortality, morbidity or social capital, that determines a numerical value representing the social vulnerability of a given geographical unit (Birkmann, 2005). However, as will be shown in the literature review, the majority of vulnerability indices that have been produced are largely reliant upon generic, geographically broad indicators, such as percentage of population below the national poverty line or ethnic composition, which do not provide the precision required for the fine-resolution geography under examination here or that is required by local councils or NGOs who need to adequately understand social vulnerability within an area to plan appropriately. Such indicators have been shown by others to be able highlight areas of vulnerability, but we argue that an array of specific indicators spanning the many aspects 
of modern life - from accessibility and education to the strength of local economies - are required to gain a more substantive knowledge of modern social vulnerability.

In this paper, we examine social vulnerability through the creation of an Open Source Vulnerability Index (OS-VI). A deductive indicator-based approach is utilised to incorporate a range of vulnerability indicators previously shown to define and influence vulnerability. In addition to vulnerability indicators, the OS-VI incorporates the risk of flooding when determining an area's level of social vulnerability. Unlike many hazard mapping studies, it is not just proximity to the flood zone that is included within the OSVI; consideration is paid to the loss of capabilities and the importance of key services (health care, food stores and employment centres) with the inclusion of measures of accessibility factored in to the OS-VI. The index was developed using open-source mapping and analysis software and is composed completely of open-source data from national data sets. The OS-VI was designed at the national level with a resolution of approximately 1500 people per Census tract, with data for all proxy indicators available across the entirety of England and Wales. For this paper, a case study is presented concerned with one English county, Norfolk.

We first review past vulnerability analyses, focusing on the act of measuring and assessing vulnerability: indicator selection and index weighting as well as the inclusion of accessibility within vulnerability analyses. Building upon the critical review of the vulnerability literature, we present the choice of indicators used and the mapping processes utilised to construct the index. The resultant OS-VI maps are presented and discussed as well as a case study looking at accessibility to hospitals. We conclude with reflections on the work undertaken and the potential refinement of the index and its future use.

\section{Literature review}

This literature review will examine the trends within past vulnerability assessments, with a particular focus on the use of indicators to quantitatively measure vulnerability and the weighting of said indicators within vulnerability indices, followed by an examination of the role of accessibility within social vulnerability and the methods used to measure it.

Although many more challenges and debates still exist that centre on the history, conceptualisation and definition of vulnerability, we will not focus on them here and instead point the reader towards more detailed examinations of the theoretical developments of vulnerability within the academic literature (see: Adger, 2006; Blaikie, Cannon, Davies, \& Wisner, 1994; Cutter, 1996; Cutter, Emrich, Webb, \& Morath, 2009; Liverman, 1989).

\subsection{Vulnerability assessments}

Countries, counties and cities are not homogenous, but are instead made of unique 
communities that represent the most affluent and privileged, as well as the most destitute and deprived. Vari- ations in socio-economic and health vulnerabilities exist in space and time and indicators are available that are regularly and systematically collected at a resolution small enough to allow quantitative measurement and mapping of such variations at a community level (Cutter, Burton, \& Emrich, 2010).

A vulnerability perspective has been shown to focus the attention of social research on the diversity within populations; concentrating on the broader social, cultural and economic factors that influence a community's vulnerability and moving focus away from a singular examination of the presence of hazards (Van Zandt et al., 2012). Vulnerability assessments are often the first step to identifying those groups in society who may require added assistance during an emergency (Blaikie et al., 1994; Morrow, 1999; Müller, Reiter, \& Weiland, 2011). However, due to its somewhat ambiguous nature, many assessments of vulnerability have, to a certain degree, been vague, oversimplified or ill-structured (Kværner, Swensen, \& Erikstad, 2006; Müller et al., 2011).

Most vulnerability assessments examined were found to be concerned with locating physical structures or population concentrations at risk within known hazard-prone areas (Kværner et al., 2006; Müller et al., 2011). However, as events such as Hurricane Katrina showed, the nature of the population - race, ethnicity, wealth, employment, income, and so on - is just as important a factor as where that population resides (Long, 2007; Oxfam America, 2009; Tate, 2013).

The majority of the research into vulnerability assessments undertaken over the past 20 years has focused on developing frameworks that are applicable to various systems, scales and hazards (Stângă \& Grozavu, 2012; Taubenböck et al., 2008). However, scale and versatility have been identified as major constraints of many vulnerability assessments (Preston, 2012). Much of the literature examined was found to focus on, and assign great premium to, economic aspects of life, namely income (Preston, 2012), and to limit research by geography (state, territory or census block) and the range and applicability of indicators used. Relatively few studies have been operationalised in real-world settings (Cutter et al., 2009), with fewer still replicable outside of their original focal zone. Assessments are often designed with a focus on a specific geo-graphical area, often limiting their universal usage (Engle, 2011), or the methods and data used often render the indices inappropriate or incompatible with other areas, timescales or systems (Lankao \& Qin, 2011). Further, limited attention was found to be paid to open-source data usage, with proprietary data and technology utilised widely. Few studies were found to have produced an index that could be freely and easily utilised and adapted by NGOs and communities (Garbutt, 2013). Due to these problems of comparability between indices, variables and methods, vulnerability assessments are best thought of as an heuristic illustration of the conditions within the study area, be it existing or anticipated, and not as a predictive tool (Cutter et al., 2009). In terms of scale, vulnerability assessments are generally undertaken at one of three levels: household, regional or national. Many studies exist that examine relative vulnerability 
across countries (Webber \& Rossouw, 2010), such as Turvey's (2007) composite vulnerability index (CVI) of 100 developing countries, but rarely is attention paid to the differing vulnerability of regions within these countries. At the local level, there is a large and growing body of work examining local-level vulnerability, be it at the household level (Bird \& Prowse, 2008) or Cutter's place-based vulnerability indices centred upon United States Census Bureau block-groups (Cutter, Mitchell, \& Scott, 2000) or later community resilience studies undertaken at the larger county level throughout coastal US states (Cutter, 2006; Cutter, Barnes, \& Berry, 2008). There is a growing body of literature on vulnerability science that seeks to increase the usefulness and use of vulnerability assessments, with an academic focus on quantitative measures of vulnerability and the developments of a universal metric or measurement tool for vulnerability assessments (see: Cutter et al., 2009; Jones \& Thornton, 2003; Kasperson \& Kasperson, 2001; Polsky, Neff, \& Yarnal, 2007). However, much of the literature reviewed also advocates a fineresolution, place-based, assessment methodology in an attempt to produce more local and relevant observations (Barnett, Lambert, \& Fry, 2008). 2.1.1. Indicators of vulnerability

Indicators - 'quantitative measures intended to represent a characteristic or a parameter of a system of interest' (Cutter et al., 2008, p. 7) - are regularly used within vulnerability science to produce a single universal value that represents vulnerability at a particular temporal or spatial scale or location. A wide variety of indicators and assessment models are in use with common indicators including: mortality, morbidity, social capital and physical assets (see: Environmental Sustainability Index (Esty, Levy, Srebotnjak, \& de Sherbinin, 2005), Human Development Index (Anand \& Sen, 1994; Burd-Sharps, Lewis, \& Martins, 2008), Human Well-being Index (Prescott-Allen, 2001) and Social Vulnerability Index of Climate Change in Africa (Vincent, 2004)). The proxies available for each indicator are yet more numerous (Rygel, O’Sullivan, \& Yarnal, 2006).

A wide-ranging selection of relevant vulnerability indicators is presented within the literature. Cutter, Boruff, and Shirley (2003) alone present a version of their index that utilises 42 indicators. However, this project was concerned with vulnerability in a rural/urban region within a developed country, which means that not all vulnerability indicators identified within the literature are appropriate. For example, common indicators used within vulnerability indices are measures of political stability, access to education and literacy rate (Mustafa, Ahmed, Saroch, \& Bell, 2011; Patt, Tadross, Nussbaumer, Asante, $\&$ Metzger, 2010). These indicators are arguably inappropriate for use within developed countries. Other indicators utilised in earlier studies, such as social-capital religion, local asset value and civic involvement (Müller et al., 2011), are unsuitable due to limited data availability.

Challenges to the production of vulnerability metrics, especially a universal index, and the use of such indicators do exist, with vulnerability indices limited by the lack of consensus on a strict definition of vulnerability across the discipline; selection of indicators; determination of indicator importance; data availability, quality and validation; and 
difficulty in quantifying social inter- actions and measuring concepts such as institutional capacity or readiness (Müller et al., 2011). Furthermore, indicators, like models and indices, represent reality imperfectly. The reliance upon measurable data, both quantitative and qualitative, to produce a vulnerability index limits it to those vulnerability components that are quantifiable (Moldan \& Dahl, 2007). Interactions and feedbacks exist that are not sufficiently understood and thus cannot be factored into the production of accurate indicators (Damm, 2010). The impact of these 'non-quantifiables' must be gleaned from qualitative research, working with NGOs, for example, to further elucidate the find- ings from studies like the one presented herein.

To be effective, vulnerability indicators must be appropriate, representative of the phenomenon under examination, credible and feasible (Moldan \& Dahl, 2007, Niemeijer, 2002). However, methodological trade-offs are often necessary and a balance between these dimensions, as well as scale and cost, is required to produce legitimate and usable indicators (Damm, 2010). As with using too broad a geographic scale of analysis - county over Census tract, for example - the use of general, broad-based indicators can reduce the effectiveness of the index as populations under analysis are grouped and classified too coarsely, perhaps even stereotyped (Goss, 1995), and the nuances of vulnerability and local minutiae are lost. Similarly, vulnerability represents social geography (Cutter, 2006) and, as such, indicators must vary with changing geography (Rygel et al., 2006). Indicators infer knowledge of a system (Balica \& Wright, 2010) and to fully understand the vulnerability system, we believe, the indicators used should be as locally relevant as possible.

\subsubsection{Weighting}

The process of weighting vulnerability variables is often idiosyncratic and is the subject of much debate (Bohringer \& Jochem, 2007; Brooks, Adger, \& Kelly, 2005; Morse, 2004; Yoon, 2012). Two camps exist whereby studies either treat all factors equally within an index, or they apply weightings based upon perceptions of indicator importance, often with weightings assigned with little to no input from those within the society being examined (Dibben et al., 2004).

Many vulnerability assessments develop weighting schemes and believe that this is necessary to accurately assess vulnerability as not all elements within society play an equal role in creating, fostering or reducing vulnerability (Haki \& Akyurek, 2004; Meyer, Haase, \& Scheuer, 2007). For example, the English Indices of Deprivation, which provides a relative measure of deprivation across England at the Lower Layer Super Output Area (LSOA) resolution, assigns a combined $45 \%$ weighting to issues of income and employment and $13.5 \%$ to issues around health and dis- ability. Similarly, in developing their weighting schemes, Rygel et al. (2006) ranked the factors within each indicator to assign importance; Cox, Rosenzweig, Solecki, Goldberg, and Kinney (2007) assigned weightings based on the per cent variance explained by each factor; Brooks et al. (2005) employed focus groups to identify vulnerability indicators, as well as relying on those previously identified by earlier studies, and to provide weightings for each indicator 
chosen.

However, many vulnerability studies examined preferred not to assign weights to their chosen indicators, claiming that they are of equal importance to the calculation of vulnerability or are independent of each other (Yoon, 2012) or that insufficient evidence exists to accurately assign importance to any one demographic factor over another to produce a robust weighting system (Fekete, 2011). However, Fekete (2011, p. 1167) does acknowledge that 'the avoidance of weight- ing is in itself a certain kind of weighting ... because not weighting means equal weighting within the aggregation of input variables or indicators'.

\subsection{Accessibility}

Accessibility to key services is severely affected during an emergency, particularly during flood events where people can be stranded in their homes, roads can be washed out, and services damaged or stopped, further compounding the vulnerability of individuals or groups, particularly the elderly. Although the immediate health impacts of floods (deaths and injuries caused by drowning) are relatively rare in the UK compared to the mediumto long-term effects (particularly psychological stress) (Reacher et al., 2004; Tapsell \& Tunstall, 2006), timely access to a hospital during such an emergency situation remains a requirement that can reduce a person's overall level of risk (Campbell et al., 2000; Nicholl, West, Goodacre, \& Turner, 2007). However, according to the Department for Transport (DfT), the UK Government department responsible for the majority of the UK's transport network, accessibility to health care appears to be getting worse, with less than one-third of the population having 'reasonable' access to a hospital (defined as travel time under 30 minutes) (DfT, 2012). The most striking element of the DfT accessibility data are the differences between the UK's rural and urban communities: rural resi- dents are required to travel for up to 29 minutes on average to access key services (hospitals, food stores, employment centres, schools and town centres), compared to an average of 12 minutes for urban residents. This is an issue of growing concern, given the increasing rural popu- lation, approximately 10 million, whose residents have a far higher age profile than their urban counterparts as well as an increasing number of residents with an activity limiting health problem or disability (Office for National Statistics, 2013). It is believed that more than one million UK residents annually do not seek medical assistance and/or miss medical appointments due to limited accessibility, severely impacting an individual's health and compounding social exclusion (Nettleton, Pass, Walters, \& White, 2007).

Although a significant body of literature exists examining accessibility from a number of per- spectives (see: Higgs, 2004; Liu \& Zhu, 2004; Mavoa, Witten, McCreanor, \& O'Sullivan, 2012), much of the academic work on accessibility has focused on the impact of physical restraints or barriers, for example, topological or spatial barriers (rivers or mountains) or the impact of car ownership (or lack thereof), whereas the examination of temporal constraints on access to key services (the time taken to reach a hospital) has been the subject of far fewer empirical studies (Delafontaine, Neutens, \& Weghe, 2012). Recent 
theoretical advances and improvements in the quality and availability of data have led to an increased interest in the application of accessibility as a measure of vulnerability (Páez, Scott, \& Morency, 2012). Areas such as social exclusion (Ribeiro, Antunes, \& Páez, 2010), regional and urban planning (Comber, Brunsdon, \& Green, 2008), the economy of transportation infrastructure (Páez et al., 2012) and the location of healthcare facilities (Coffee et al., 2012; Ngamini Ngui \& Vanasse, 2012) have all seen a growing interest in accessibility. The causal relationship between transportation disadvantages and social exclusion has become central to most modern transport planning (Chen, Keith, Air riess, Li, \& Leong, 2007; Neutens, Delafontaine, Scott, \& De Maeyer, 2012; Preston \& Rajé, 2007; Scott \& Horner, 2008). Despite its importance, few vulnerability assessments were found to have included a measure of accessibility within a vulnerability assessment.

\subsection{Literature review conclusion}

Findings from this literature review have demonstrated the breadth of vulnerability analysis and the continued desire to quantify vulnerability and the many methodologies employed. However, the review revealed various widespread methodological limitations. Past work on measuring and mapping vulnerability was found to suffer from four main problems: (1) the focus on population concentrations within known hazard zones and not entire populations, potentially omitting vulnerable populations; (2) it has been limited by scale either too large to uncover local-level nuances or too insular to allow for useful comparisons at a country or larger level, often utilising site-specific data or indicators; (3) the focus on income as the key variable for measuring vulnerability, deprivation or resilience; and (4) the reliance on proprietary data and/or methodologies.

The review found a plethora of large-scale (country to near-global) attempts to assess vulnerability with a focus on relative measurements of vulnerability based predominantly on the economic aspects of life and idiosyncratic views on indicator weighting. Few studies that took account of social aspects of vulnerability (health, well-being and support) were found to realistically examine vulnerability on a local scale using an indicator-based approach.

The review identified few vulnerability assessments that included a measure of accessibility within the measurement of vulnerability, despite the recognition of its importance. Limited quantitative research was found that combined geo-demographic analysis of vulnerability and hazard mapping to produce a CVI at a national scale with a resolution smaller than county or region level. A lack of integration between academic analyses of vulnerability and governmental and non-governmental policy was also noted (Mustafa et al., 2011), with the requirements, scale, complexity and enquiry method required by both such parties being often at odds (Mustafa et al., 2011).

\section{Methodology}




\subsection{Study area}

Norfolk is a low-lying English county with an extensive coastline - 93 miles. Norfolk has a lengthy history of coastal and riverine flooding, ranging from the North Sea flood of 1953 to several less extensive, but still damaging, flood events occurring over the past half century. It is estimated that 100,077 properties in the county are at risk from flooding, with the areas of Norwich, King's Lynn and Great Yarmouth highlighted at particular risk (Carroll, 2012). It is an area with a near-equal rural/urban divide with an aged population and a low population density - 160 people per square kilometre (compared to the UK average of 407). Norfolk has limited accessibility options despite being one of the largest counties in the UK: it has no motor-way, direct access to only three primary 'A' roads (A11, A12 and A47), only one major railway station and has only two NHS hospitals with accident and emergency facilities (Norfolk \& Norwich University Hospital and Queen Elizabeth Hospital) (Figure 1).

3.2. Geography and map data Choosing the correct level of Census geography is essential to highlighting the real patterns and issues within large governmental data sets. It can be detrimental to simply choose the smallest Census tract available. When looking at fineresolution geographies, particularly Output Area (OA) and postcode level, confidentiality becomes a problem as data supplied are likely subjected to rounding to ensure anonymity when dealing with, for example, instances of violent or sexual crime or users of mental health services. In addition, choosing a level of geography such as post- codes results in a vast increase in the level of investigation and calculation required, adding strain to the GIS produced (for example, there are 2.5 million postcodes in the UK compared to 171,372 OAs). Conversely, choosing a medium-large geography, Medium Super Output Area or Local Authority (LA), would speed up investigation and allow for easier integration of health and crime data, but reduce the applicability of results at a community/neighbourhood level, as a single vulnerability score would be produced for in excess of 15,000 people.

Examination of the different geography products available led to the decision to use the LSOA boundaries for final analysis and visualisation (Figure 2). LSOA has a minimum population of 1000 , with an overall mean of 1500 , providing a sufficiently fine-grain detail to examine 


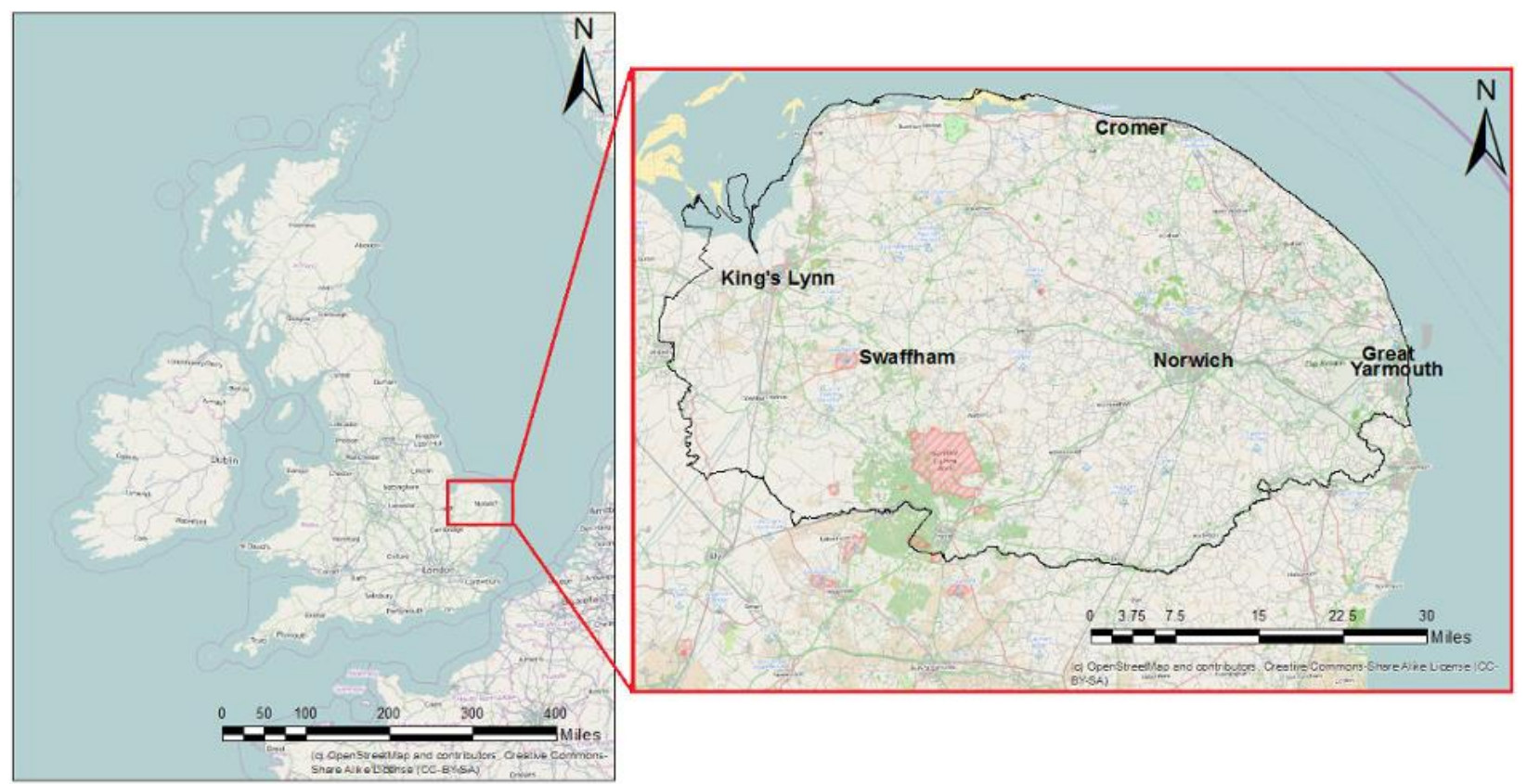

Figure 1. Study area map showing the location of the county of Norfolk and its major urban towns. 

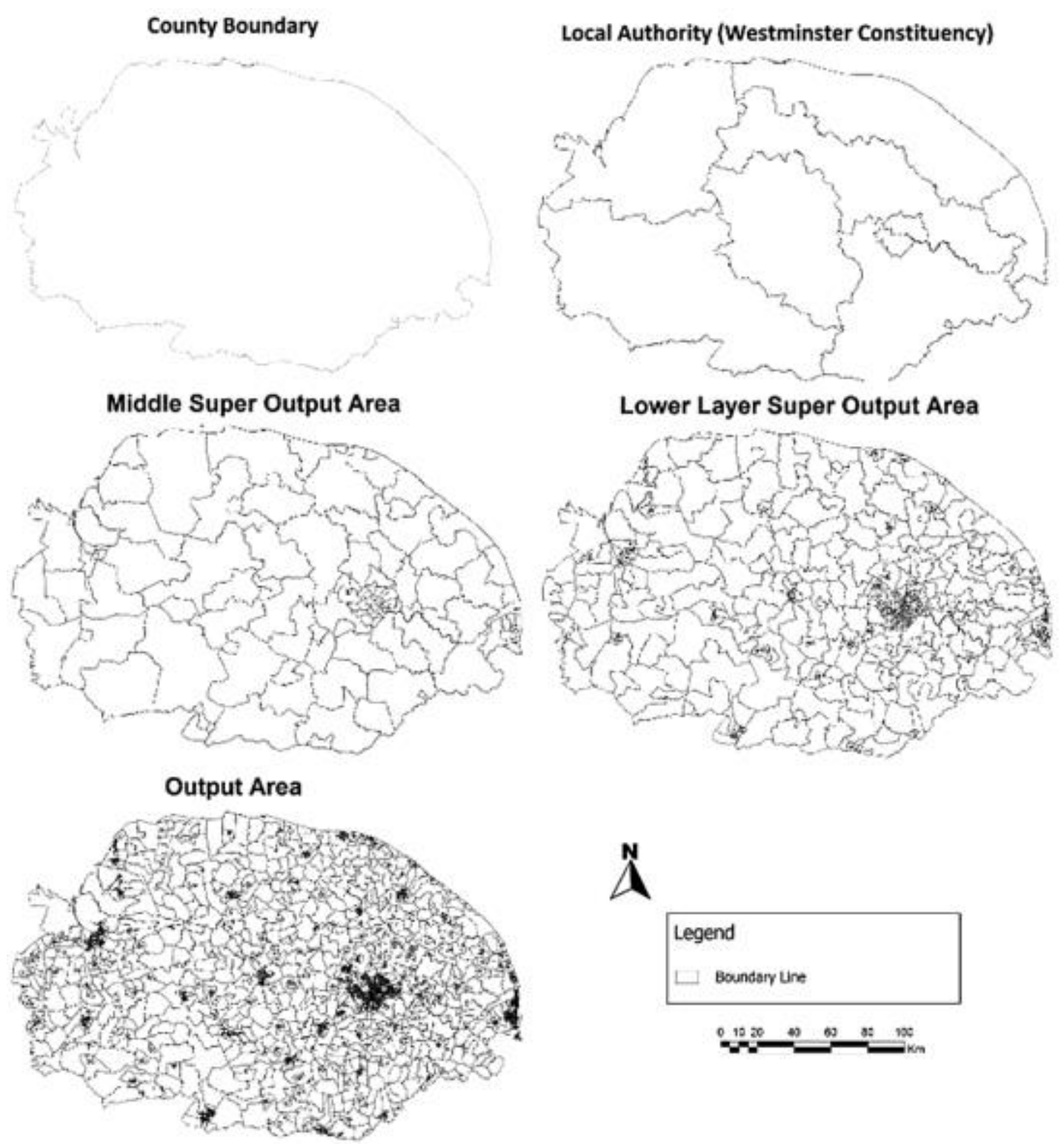

Figure 2. A comparison of ONS census geography/boundaries.

vulnerability at a community level. In addition, key data sources, namely Office for National Statistics (ONS) Census, readily supply data at the LSOA level and the resultant LSOA-based OS-VI would be easily compared to the English Indices of Deprivation (Index of Multiple Deprivation (IMD)) and Experian's MOSAIC classification (see Section 5.2). There are 539 LSOA in Norfolk, 34,753 throughout England and Wales.

This project takes full advantage of the open-source community and utilises a wide range of open-source digital maps supplied by the Ordnance Survey (OS) and ONS and key service location data provided by OpenStreetMap (OSM). It was hoped that OSM road data could be utilised for routing purposes. However, when OSM road data were compared to OS OpenData data, a significant number of roads, particularly local residential streets and small country tracks, were either missing or significantly misaligned and lacking meta-data 
required for robust routing. Thus, it was decided to use an OS MasterMap Integrated Transport Network (ITN) road data set, freely available from the OS under their OpenDataTM initiative to develop a routable road map.

\subsection{Flood data}

UK flood data, specifically information pertaining to flood affected areas and flood defences, is freely available via the Environment Agency's website. It was decided that, for this project, the type of flooding (tidal, fluvial or ground) was not required for analysis, just the knowledge that a certain area was or was not within a flood zone. It was decided to plan for the 'worst- case scenario' and utilise the 'extreme flooding' scenario: $0.1 \%$ (1 in 1000) or greater chance of happening each year (Figure 3). In addition, the LSOA Centroids, which represent a summary single reference point of how the population at census time was spatially distributed and grouped within that LSOA, were utilised to define those centroids within the flood zone. This was utilised within accessibility analysis and as part of a hazard indicator.

\subsection{Accessibility mapping and key services}

As stated in the Literature Review, access to key services is an important aspect of vulnerability and the loss of capabilities that accompany limited access to key services is well known (Miller, 2003). The UK Government states that 30 minutes is a 'reasonable' time to access a key service (DfT, 2004). Thus, to gain a greater understanding of accessibility within Norfolk, key services within the study area, including hospitals, general practitioner (GP) surgeries, large food stores and schools, were mapped using data from OSM.

Travel time to a hospital was chosen for analysis not due to the potential increased demand for hospital access caused by the flood event - there is little evidence in the UK to suggest that flooding leads to an increase in hospital demand in the immediate aftermath of a flood (Bennet, 1970; Floyd \& Tunstall, 2004; Tunstall, Tapsell, Green, Floyd, \& George, 2006) - but due to the vital health, well-being and social care services that hospitals provide to the rural and largely elderly communities within the study area. Any reduction or disruption to these services due to reduced service provision as emergency response work takes priority (Kaźmierczak \& Cavan, 2011) and routine social care personnel respond to those impacted by the floods (World Health Organization [WHO], 2002) or the loss of service due to hospital closure or damage (Greater London Authority, 2013; WHO, 2002) or reduced accessibility due to restricted transport options or damaged trans-port systems (Aday, 2001; Morath, 2010; WHO, 2002) could exacerbate pre-existing community vulnerabilities, health concerns and the stresses of flooding (Hajat et al., 2005).

Service Area and Closest Facility analysis was undertaken using QuantumGIS and the routing metadata within an OS ITN road data set(Figures 4 and 5). It was assumed that all journeys started at the LSOA Centroid and were taken in a car travelling at the maximum 
speed allowed. The impedance was time and the fastest routes were calculated. Analysis was repeated under flooded conditions where it was assumed that, under the 'worst-case scenario', all roads within the flood zone would be impassable and that key services would likely be damaged or inac- cessible. Thus, roads and key services within the flood zone were restricted. Accessibility results fed into the OS-VI, with any LSOA registering travel time to a key service above the average receiving a score of one and all others a score of zero. A case-study example of those LSOA that were unable to reach a hospital due to the flood zone restrictions is presented.

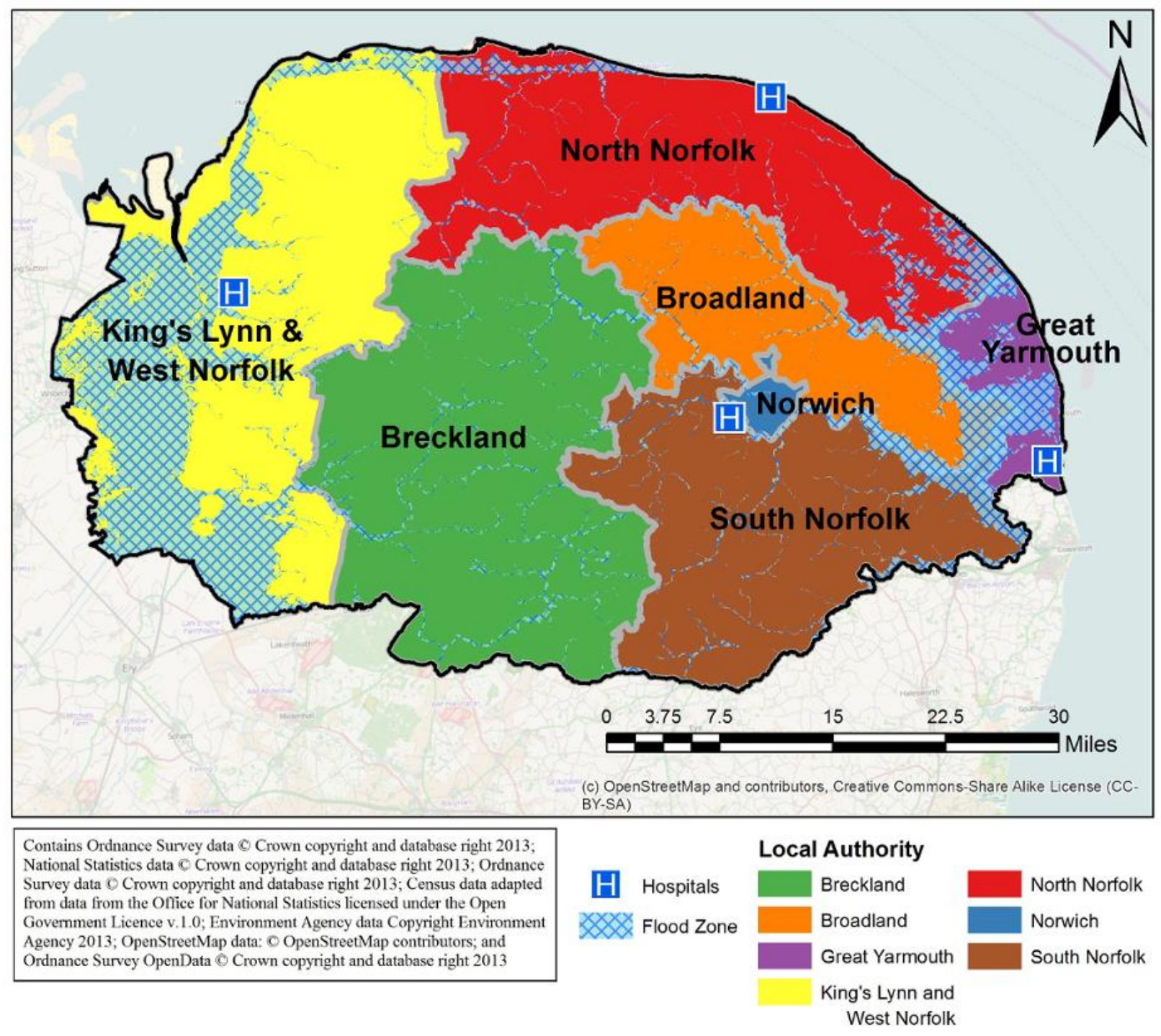

Figure 3. Norfolk local authorities with flood zone overlay. 

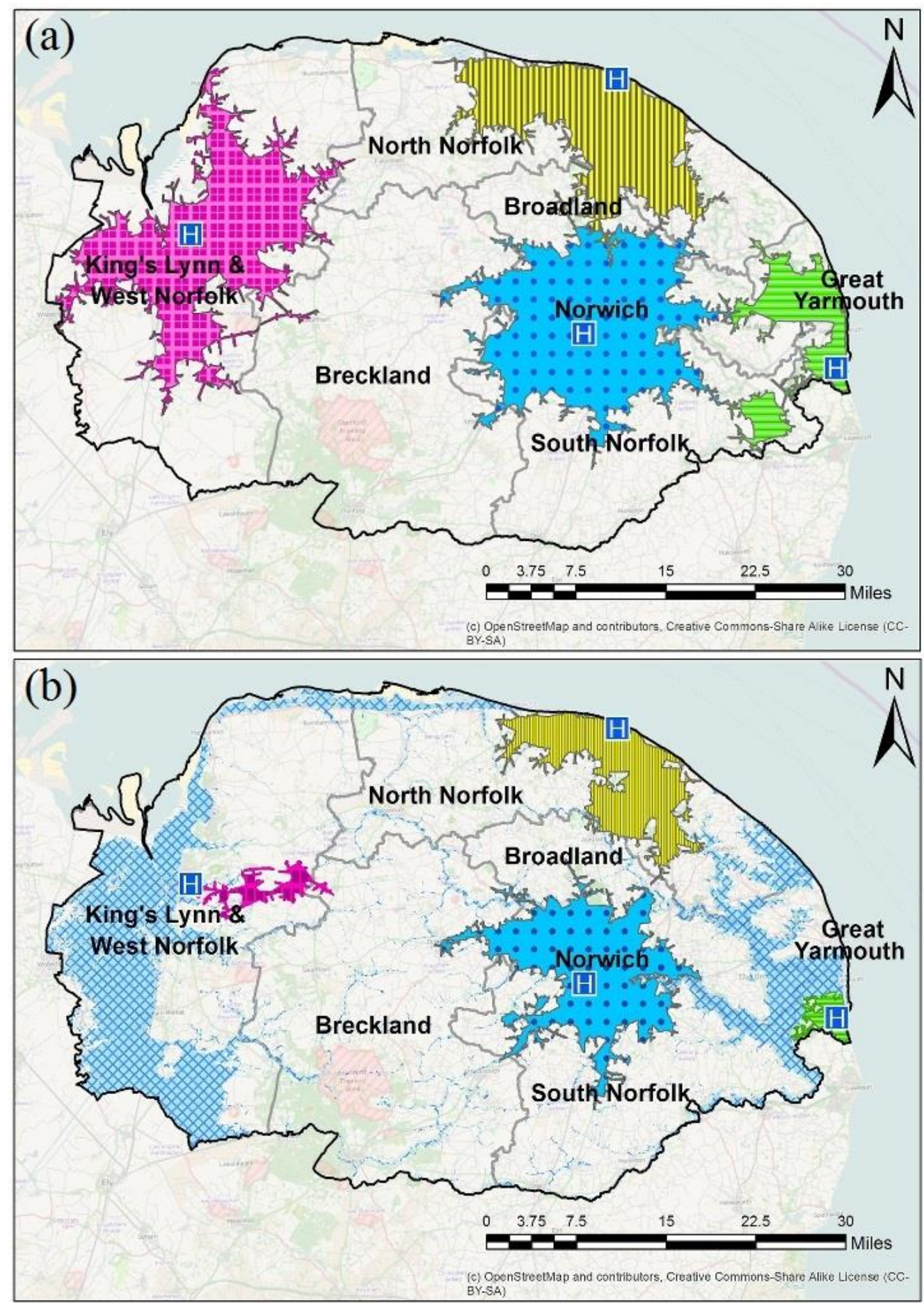

\begin{tabular}{l} 
Contains Ordnance Survey data $\otimes$ Crown copyright and database right 2013; \\
National Statistics data $\odot$ Crown copyright and database right 2013 ; Ordnance \\
Survey data $\&$ Crown copyright and datakase right 2013 ; Census data adapted \\
from data firom the Office for National Statistics licensed under the Open \\
Government Licence v.1.0; Environment Agency data Copyright Environment \\
Agency 2013; OpenStroetMap data: $\otimes$ OpenStreetMap contributors; and \\
Ordnance Survey OpenData \& Crown copyright and database right 2013 \\
\hline
\end{tabular}

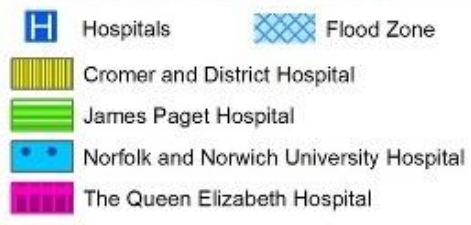

Figure 4. (a) Service area -30 minutes travel time from hospitals under non-flooded conditions and (b) Service area - 30 minutes travel time from hospitals under flooded conditions. 

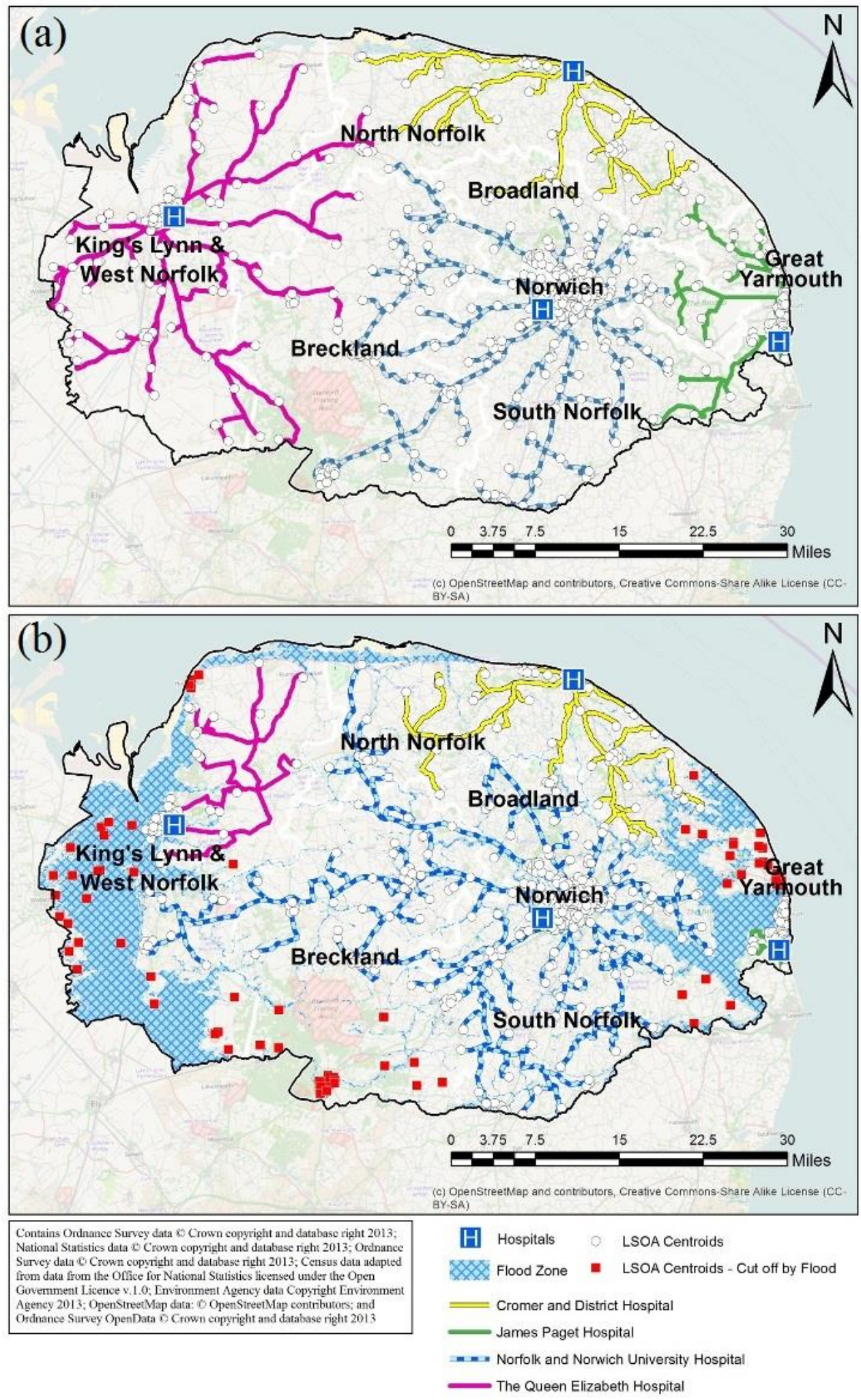

Figure 5. (a) Closest facility analysis to nearest hospital under non-flooded conditions and (b) closest facility analysis to nearest hospital under flooded conditions. 


\subsection{Identification and analysis of vulnerability indicators}

The selection of indicators had two controlling factors: (1) justification of its relevance to the measure of vulnerability based upon extant data/literature and (2) the availability of open- source data presented at an appropriate geography that is of consistent quality. Although there is no agreement on a single set of vulnerability indicators within the wider literature, there is agreement that vulnerability stems from elements related to economic and material wealth, health, institutional support, accessibility and the presence of hazards (Bruneau et al., 2003; Gunderson, 2009). Subsequently, through literature analysis and focus group discussions with experts from NGOs and community groups affected by flooding, a 'short list' of 77 key vulnerability indicators was produced that met the controlling factors. Further discussions reduced the list to a set of four category elements, which are further divided into sub-categories and finally proxy variables and their respective indicators. In total, 53 different vulnerability indicators were chosen to form the OS-VI (Table 1). Data were acquired, examined and prepared as a full England and Wales data set and filtered for the Norfolk case study herein.

\subsection{Development of a vulnerability index}

A vulnerability 'score' was produced for each of the 539 LSOAs of Norfolk, England. All indicators were normalised, translated into scale-free relative frequencies per LSOA and reduced to a binary format: either a zero or a one, with a zero representing no vulnerability and a one representing the presence of vulnerability. The indicator for each vulnerability variable is based upon the average figure for that variable within England and Wales as a whole, that is, for the variable 'percentage of population of LSOA aged 16 or under'. If the result is above the national average, the LSOA is assigned a binary vulnerability score of one for that variable, or if the result is below the average, it is assigned a zero. It was felt that the use of an average for each vulnerability indicator (both national and county) offered a suitable measure of potential vulnerability by representing a baseline whereby those below the average are arguably more vulnerable than those above the baseline.

It was decided that a transparent and easy-to-understand indicator system would be best, given the intent to use the system outside of academia. Whilst a plethora of weighting methods exist that are subjective or reliant upon data analysis, such methods do not adequately reflect the priorities of decision-makers (Cutter et al., 2010; Esty et al., 2005). As such, an equal-weighting system was utilised for the OS-VI, but team leaders from the consulting NGO were provided with an interactive 'dashboard' whereby they could define the weightings used for the calculation of each vulnerability category so that they could produce an index that represents the priorities of their department.

Two separate OS-VI were produced, one based upon variable averages for England and Wales as a whole and another that examines Norfolk in isolation. This was done to provide information on vulnerability in Norfolk in relation to that of England and Wales but also to identify vulnerability within Norfolk under a local context. The intention of the National 
OS-VI was to present the vulnerability of Norfolk in relation to England and Wales, not in context to England and Wales. What the presented National OS-VI does not show is the rating of any given Norfolk LSOA in relation to the other 34,214 LSOA in England and Wales. Only Norfolk LSOA was ranked. It was out of the scope of this project to produce an entire National OS-VI. Although several variables were processed at the national level, several key variables, namely those relating to flooding and accessibility, could not be processed to the extent necessary within the given timeframe. The Local OS-VI was created using average figures for Norfolk only. This localised OS-VI provided a more place-based examination of vulnerability.

\subsection{Visualising the OS-VI}

OS-VI results were ranked (LSOA with the lowest cumulative vulnerability score ranked 1 and the highest score ranked 539), divided into four vulnerability ratings and, following discussions with NGO sponsors and beneficiaries, visualised in the near-universal and easily understood traffic light style graduated symbology that allows for quick interpretation and is widely recog- nised within risk and emergency management sectors (see Cabinet Office, 2013):

1) low vulnerability (1-134);

2) low to moderate vulnerability (135-269);

3) moderate to high vulnerability (270-404) and

4) high vulnerability (405-539).

As is given, areas rated high indicate areas with a relative higher level of vulnerability because a high number of assessed variables were above average for that LSOA in the National or Local OS-VI, suggesting that that LSOA is in a more vulnerable state relative to the average National or Norfolk LSOA. Similarly, areas rated low indicate areas with a relative lower level of vulnerability and suggest that LSOA is in a less vulnerable state relative to the average National or Norfolk LSOA.

\section{Results}

\subsection{The open-source vulnerability index}

As can be seen in Figures 6 and 7, the National and Local OS-VI display a similar vulnerability distribution. No significant trend was noted that could explain the changes between the two OS- VI. Both OS-VI present vulnerability within Norfolk as following a general radial pattern around the major urban areas, namely the city of Norwich, with vulnerability high within the urban centre and decreasing outward. A low vulnerability 'ring' can be seen to encircle Norwich, representing the relatively affluent suburbs of Norwich.

The OS-VI scores range from 12 (low vulnerability) to 45 out of 53 (high vulnerability) 
for the full National OS-VI, with a mean score of 24 , and a range of 6-45 out of 53 for the Local OS-VI, with a mean of 22. With the exception of two LSOA, the most vulnerable LA is Great Yarmouth, with approximately $85 \%$ of LSOA in both indices rated high or moderate-high. Topping off the list as the most vulnerable LSOA is Southtown \& Cobholm in Great Yarmouth (E01026635), with a vulnerability score of 45 out of 53 in both indices. This is expected given the area's deprived economy and housing, as well as the general poor health of residents and the presence of a flood hazard across $25 \%$ of its area. In comparison, the least vulnerable LA is Broadland, with $91 \%$ and $86 \%$ of LSOA in that area rated low or low-moderate in the National OS-VI and Local OS- VI, respectively. The least vulnerable LSOA within the National OS-VI was Town (E01026945) in South Norfolk with a score of 12 out of 53. Sprowston Central (E01026556) in Broadland is the least vulnerable LSOA in the Local OS-VI, with a vulnerability score of 6 out of 53.

Table 2 shows the variables that contribute the most to the vulnerability scores recorded within the England and Wales OS-VI. As can be seen, all 539 LSOA within Norfolk recorded a drive time to a food store in excess of the national average. This was not unexpected, given the study area's rural geography, but does represent a major source of vulnerability, particularly given the elderly nature of the area's population (390 LSOA recording above-average elderly populations) and its poor health and mobility (366 and 326 LSOA recording above-average number of residents report- ing limited actions and long-term health problems/disability, respectively).

The LSOA with a high vulnerability rating are characterised by a disproportionate mix of urbanised towns or cities, $70 \%$, compared to rural towns or villages, which account for just $30 \%$. In comparison, the urban-rural divide within those LSOA with a low vulnerability rating is roughly equal, $49-51 \%$. For those areas with a low-moderate or moderate-high rating, the urban-rural divide is approximately $40 \% / 60 \%$. Norwich, which is entirely urbanised, recorded only one LSOA with a low vulnerability rating within the National OS-VI, with $73 \%$ of Norwich LSOA recording moderate-high or high ratings.

\subsection{The impact of flooding on vulnerability}

In total, 161 of 539 LSOA (30\%) in Norfolk were found to be impacted by flooding and saw their OS-VI ratings increase: 110 LSOA were cut off from hospitals during the flood scenario; 57 had more than $50 \%$ of their area within the flood zone; and 33 LSOA Centroids were within the flood zone. Only six LSOA recorded all three flood risks, all within the LA of Great Yarmouth and Kings Lynn and West Norfolk.

Excluding those within the urban centre of Norwich, the major clusters of LSOA with a high vulnerability rating can be seen to loosely match those areas with greater exposure to the flood zone (Figure 8). Great Yarmouth in the East and Kings Lynn and West Norfolk to the West account for $75 \%$ of those areas that received a high vulnerability rating and are impacted by flooding. Analysis found that $40 \%$ and $37 \%$ of those LSOA with a high or moderate-high vulnerability rating were impacted by flooding in some way, compared to 
just $20 \%$ and $22 \%$ of those with a low or low-moderate rating in the National and Local OS-VI, respectively. Furthermore, $79 \%$ and $90 \%$ of those LSOA with the majority of their area within the flood zone recorded a high or moderate-high vulnerability rating in the National and Local OS-VI, respectively.

\subsection{The impact of accessibility on vul nerability}

Accessibility analysis found that travel time to a hospital in normal, non-flooded, conditions ranged from 1 to 62 minutes. Norwich was the most accessible area in terms of drive time, with most key services reachable within an average of 12 minutes. Breckland and Great Yarmouth were the least accessible LA: travel time ranged from 19 to 62 minutes, with an average of 41 minutes in Breckland; and 90\% of LSOA recorded travel time in excess of 30 minutes in Great Yarmouth. The LSOA Suffield Park (E01026778) in North Norfolk recorded the lowest drive time under both 'normal' and 'flooded' scenarios, just 1 minute. 

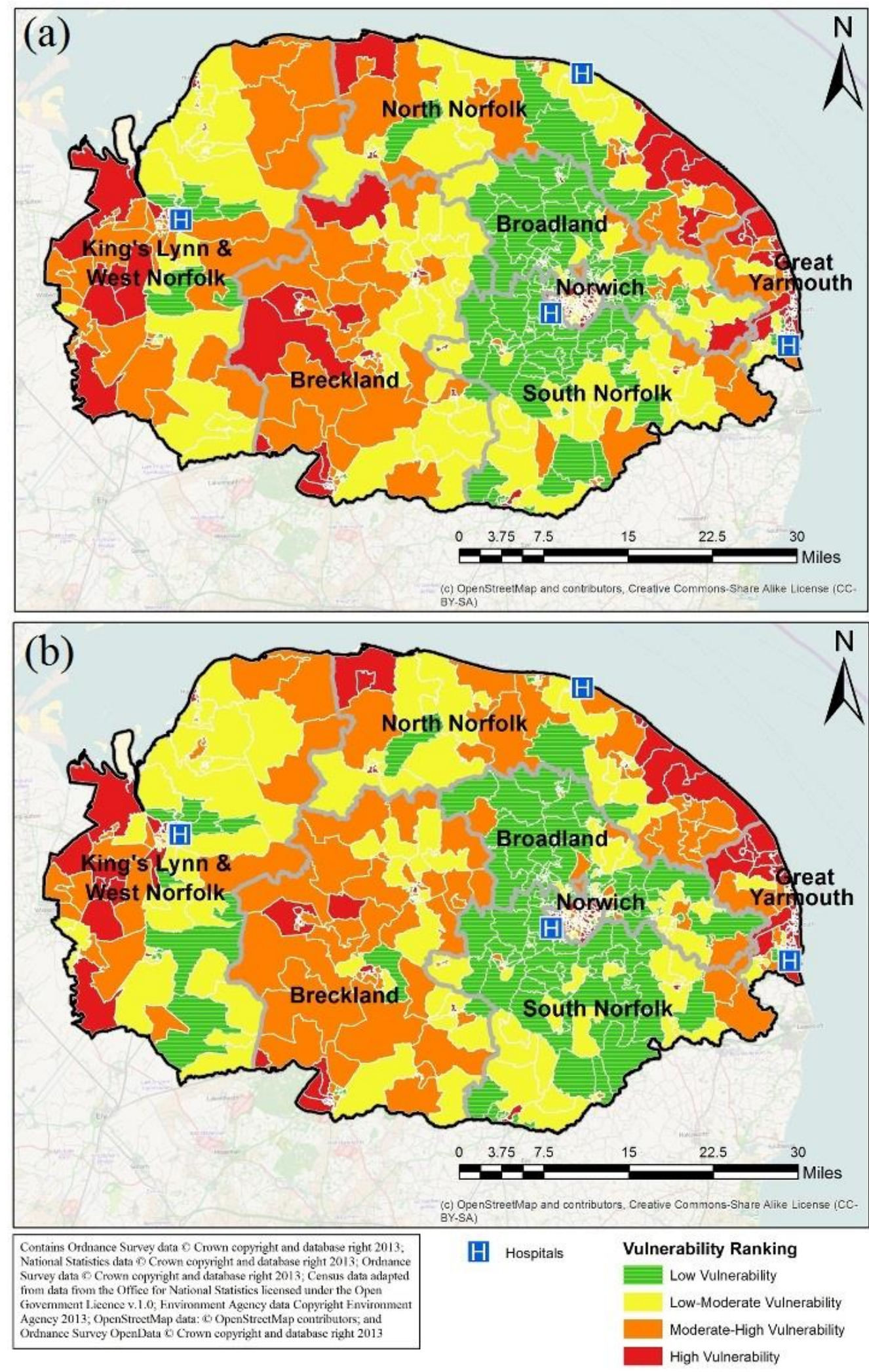

Figure 6. (a) Local OS-VI and (b) National OS-VI. 

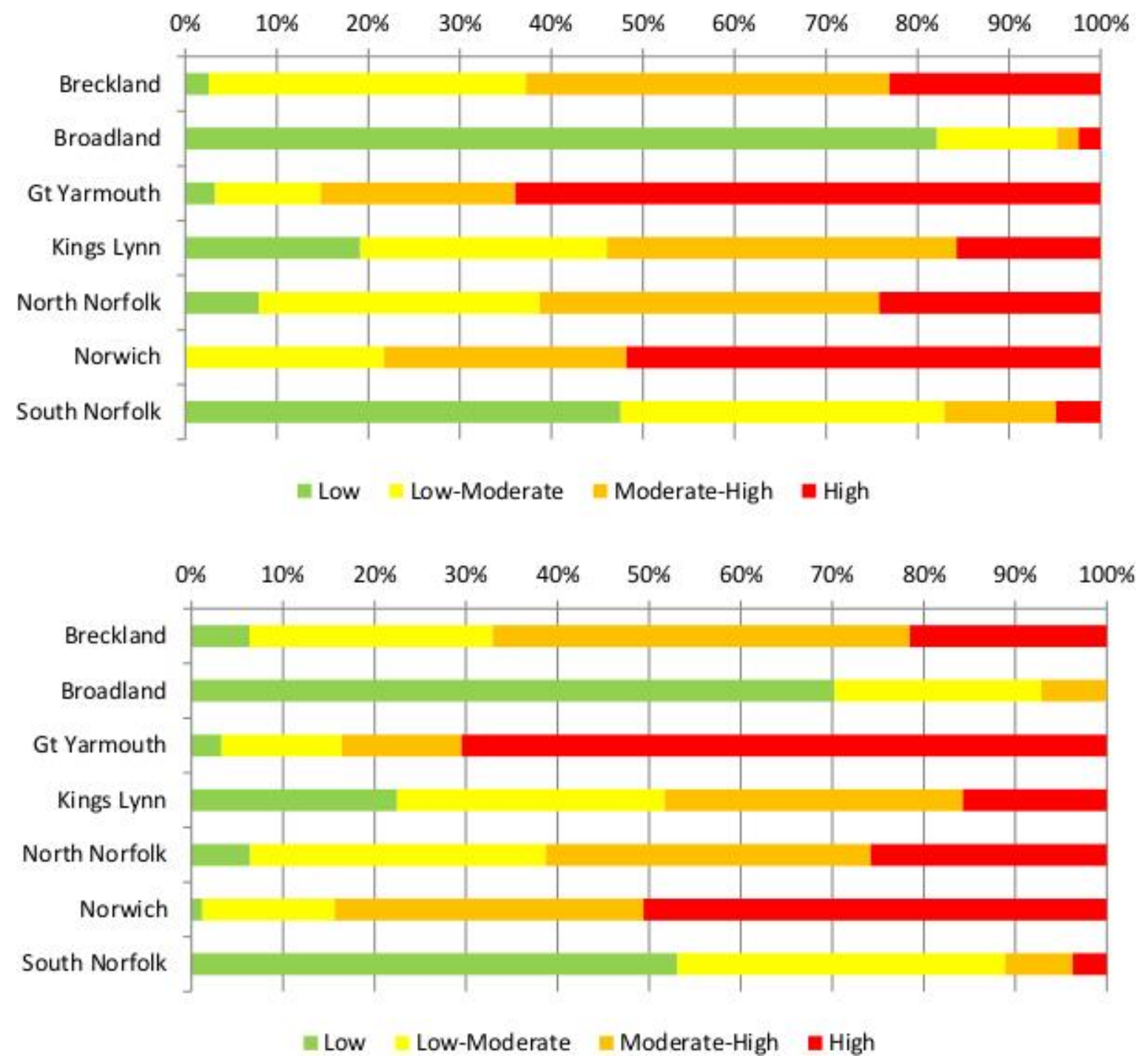

Figure 7. (a) Proportion of each LA in local OS-VI by OS-VI rating and (b) proportion of each LA in national OS-VI by OS-VI rating. 
Table 2. Variables contributing most to the vulnerability score.

\begin{tabular}{|c|c|c|}
\hline Rank & $\begin{array}{l}\text { Total number of } \\
\text { LSOA (out of 539) } \\
\text { recording variable }\end{array}$ & Variable \\
\hline 1 & 539 & LSOA with car drive time to a food store above average \\
\hline 2 & 537 & $\begin{array}{l}\text { Percentage of lone parent households in LSOA with dependent } \\
\text { children above average }\end{array}$ \\
\hline 3 & 534 & $\begin{array}{l}\text { Percentage of LSOA residents providing care between } 20 \text { and } 49 \\
\text { hours per week }\end{array}$ \\
\hline 4 & 390 & Percentage of LSOA residents aged $65+$ above average \\
\hline 5 & 374 & Percentage of LSOA households with below average median income \\
\hline 6 & 372 & Percentage of LSOA residents who are female above average \\
\hline 7 & 371 & Percentage of LSOA residents with no formal qualifications above average \\
\hline 8 & 366 & $\begin{array}{l}\text { Percentage of LSOA residents reporting limited actions due to } \\
\text { long-term health problems/disability }\end{array}$ \\
\hline 9 & 326 & $\begin{array}{l}\text { Percentage of one-person households whose occupant reports a } \\
\text { long-term health problems/disability }\end{array}$ \\
\hline 10 & 322 & $\begin{array}{l}\text { Percentage of LSOA residents providing care in excess } \\
\text { of } 50 \text { hours per week }\end{array}$ \\
\hline 11 & 313 & Percentage of LSOA residents working $49+$ hours per week \\
\hline 12 & 309 & Percentage of LSOA households with two or more deprivation dimensions \\
\hline
\end{tabular}




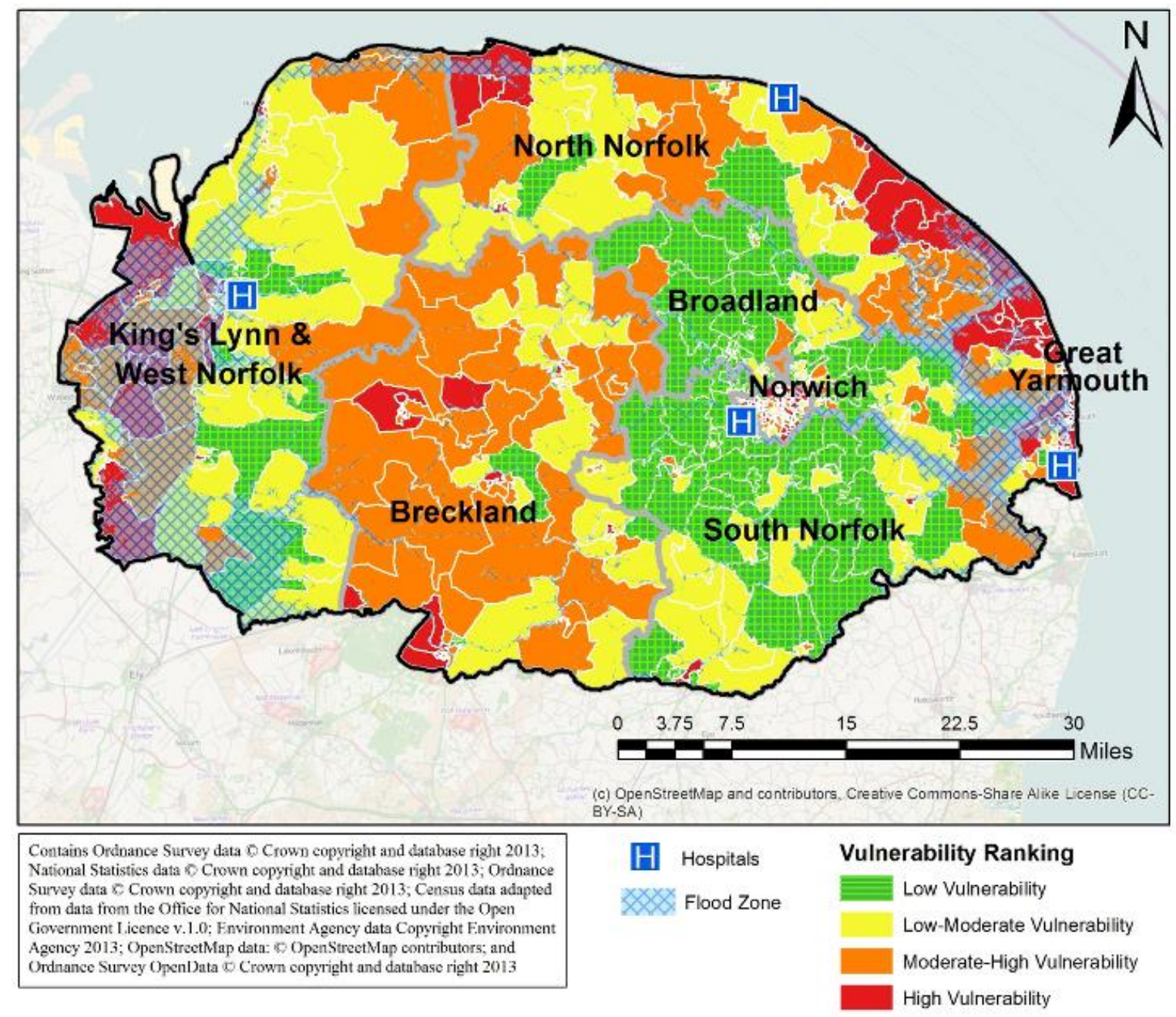

Figure 8. National OS-VI with flood zone overlay.

Under the flood scenario, when all roads within the flood zone were restricted, 110 of 539 LSOA could not reach a hospital, $38 \%$ of these were in Kings Lynn and West Norfolk. One hundred and fifty LSOA recorded travel times in excess of 30 minutes during normal conditions. This increases to 179 during flooded conditions, or 289 when LSOA with no access are included. Two hundred and thirty-six LSOA recorded no change in travel time. The LSOA with the largest change in travel time between 'normal' and 'flooded' conditions, and subsequently the longest overall travel time, was Watlington in Kings Lynn and West Norfolk(E01026722), which saw a 104-minute increase, from 22 to 126 minutes.

Accessibility in Norfolk is largely controlled by the rural/urban make-up of each area. Fifty per cent of Norfolk LSOA are listed as rural, with $59 \%$ of those listed as being dispersed or in a sparse setting. Travel time to a hospital in rural LSOA increased by $62 \%$ from an average of 29 minutes during non-flooded conditions to 47 minutes during the flooded scenario. For urban LSOA, travel time increased by $29 \%$ from an average of 17 to 22 minutes. 
Analysis found that average travel time to a hospital across Norfolk as a whole under flooded conditions increased by $52 \%$, from an average of 23 to 35 minutes. Norwich was again the most 'accessible' area, with average travel time remaining at 12 minutes and all LSOA available to reach a hospital. In comparison, Kings Lynn and West Norfolk saw the largest travel time increase: recording a $223 \%$ increase from an average of 21 to 68 minutes. In addition, $48 \%$ of Kings Lynn and West Norfolk LSOA Centroids could not reach a hospital. Great Yarmouth remains the least accessible LA, with $57 \%$ of Great Yarmouth LSOA unable to reach a hospital during flooded conditions and the local hospital, the James Paget University Hospital, largely cut off by the flood zone (Figures 4 and 5). The number of LSOA in Great Yarmouth without reason- able accessibility increases to $90 \%$ when those with travel time over 30 minutes are included.

\section{Discussion}

\subsection{The demographics of flood vulnerability in Norfolk}

The OS-VI not only displays the flood zones and therefore those areas at increased risk of flooding, it provides a means of highlighting those populations that are potentially more vulnerable to the impact of flooding due to their demographic characteristics. We term this the demographics of flood vulnerability: populations that are potentially more vulnerable to the identified flood risk due to its potential to exacerbate the local vulnerabilities identified by their demographics. This may be due to the area having a high proportion of elderly people or residents with health problems or the potential loss of key services during flooding, or, more likely, a combi- nation of such vulnerabilities.

Flooding was found to impact one-third of LSOA within Norfolk and a link between the presence of flood hazard in an area and its overall vulnerability was noted. Those areas with a high or moderate-high vulnerability rating are disproportionately affected by flooding, whereas only four LSOA with a low vulnerability rating were found to have the majority of their area within the flood zone. Furthermore, of those LSOA impacted by flooding, our analysis suggests that residents are also more likely to live alone and be aged 65+; be retired; have an income below the national median; be in receipt of a key benefit; lack central heating in their home; have bad or very bad health; have limited actions due to a long-term health problem/disability; provide care to another in excess of 50 hours a week; and are more likely to live in an area where travel time to key services is in excess of the national average. This suggests an underlying causal relationship between proximity to the hazard and socio-economic and health vulnerabilities - a trend noted by other authors (see: Alexander, 1993; Blaikie et al., 1994; Watts \& Bohle, 1993) - although the relationship is unclear and further study is needed.

A rural/urban divide within vulnerability was noted also. Accessibility has already been shown to be impacted by an area's rural or urban characteristics, with flooding further exacerbating rural area's limited accessibility. However, the link between an area's rural/urban make- up and its vulnerability is not as clear. A predominantly rural area's 
vulnerability appears to be more changeable. For example, North Norfolk, which is $85 \%$ rural, recorded approximately $40 \%$ low or low-moderate ratings; whereas South Norfolk, which is $68 \%$ rural, recorded approximately $80 \%$ low or low-moderate ratings. However, predominantly urban areas were found to be dominated by high vulnerability ratings. For example, Great Yarmouth, which is $64 \%$ urban, recorded approximately $80 \%$ high or moderate-high ratings and Norwich, which is completely urbanised, recorded approximately $75 \%$ high or moderate-high ratings. This implies that high vulnerability in an area is to some degree related to its urban extent: increased urban space leads to higher levels of vulnerability. However, not all urban areas are equally vulnerable, nor are the underlying vulnerabilities the same. More work is needed to uncover the relationship between rural/urban extent and the factors that influence vulnerability.

The LA of Norwich, which represents the only major city in Norfolk and the most populous region, demonstrates the rural/urban divide of vulnerability well. Within Norwich, the majority of LSOA are rated either moderate-high or high within both OS-VI. This high vulnerability urban pattern (Figure 9) is similar amongst both OS-VI and is a phenomenon noted within the literature whereby urban centres throughout the world are found to have high rates of vulnerability, as well as deprivation, and are often surrounded by more affluent suburbs with considerably lower levels of vulnerability (Erskine, 2010; Gartner, 2011; Musterd \& Ostendorf, 2013). This is evidenced by the two LA that encircle Norwich, Broadland and South Norfolk, both recording much lower levels of vulnerability within both OS-VI (Figures 3 and 6).

\subsection{Index comparison}

When both the National and Local OS-VI are compared, there is little variation within the overall distribution of the vulnerability scores. No significant trend in the changes of vulnerability ratings was determined. Between both OS-VI, the range in vulnerability scores was \pm 12 and only one instance of an LSOA vulnerability rating changing by more than one gradation, that is, from a low to high was found. Instead, most changes were more subtle, with the vulnerability rating changing by only one gradation, for example, from moderate-high to high. The vulnerability rating of Bowthorpe (E01026794) in Norwich increased from a low-moderate rating in the National OS-VI to a high rating in the Local OS-VI and represents a change in vulnerability score of \pm 3 , suggesting that the LSOA is far more vulnerable within a local context than it is relative to the rest of England and Wales. Analysis found that this was due to the LSOA having above- average unemployment amongst working-age residents as well as above-average claimants of working-age benefits, residents with low qualifications and households with female lone parents in full-time employment within the Local OS-VI. This highlights the level of detail and the local-level context that the OS-VI can reveal.

The findings from the OS-VI correspond very closely to oft-cited poverty and deprivation maps produced by, for example, the information services group Experian (Experian, 2014). In particular, those areas with a high OS-VI rating correlate well with those areas 
highlighted within the Experian maps (Rogers, 2012) as having the greatest overall risk of poverty, the largest instances of child poverty, and the largest proportion of households whose income is less than $60 \%$ of the median for England - all seen as indicators of vulnerability (DETR, 2000; Hills, 2012; Whelan \& Bertrand, 2005).

The pattern of vulnerability displayed within the OS-VI, a general radial configuration with vulnerability decreasing with distance from major urban areas, was found to differ from the pattern of deprivation displayed in the IMD 2010, a LSOA level measure of deprivation produced by the University of Oxford for the UK Government's Department for Communities and Local Government (DCLG, 2011). Contrary to the OS-VI, the IMD ranking within major urban areas, such as the city of Norwich, and several of the coastal LSOA within the flood zone are characterised by relatively low deprivation. Similarly, many of the suburban areas with low OS-VI ratings record high deprivation ratings within the IMD. Although the OS-VI and IMD are measuring different concepts - vulnerability and deprivation, respectively - the working definitions of the two concepts and the indicators being measured are deemed sufficiently similar to warrant comparison. The differences in the display of vulnerability and deprivation are undoubtedly due to the methodological differences between the two indices and, in particular, the IMD's focus on income and employment deprivation and its exclusion of hazards and accessibility measures as well as the equal weighting of categories within the OS-VI compared to the subjective weightings of domains within the IMD. Combined, the Income Deprivation Domain and the Employment Deprivation Domain within the IMD are weighted to account for $45 \%$ of the overall IMD score. An examination of the variables within these domains, all of which relate to families claiming forms of tax credits or claimants of unemployment related benefits amongst working- age residents, explains why areas along the coast that are characterised by retired populations whose age and economic status likely exclude them from those key IMD indicators record a relatively low IMD ranking, yet score a high OSVI rating. In addition, indices like the IMD more often than not focus on predominantly urban concerns, such as unemployment, benefits claimants and poor housing, to the detriment of rural concerns such as social isolation and accessibility (see: Farrington \& Farrington, 2005; Oxford Consultants for Social Inclusion, 2012; Preston \& Rajé, 2007). 

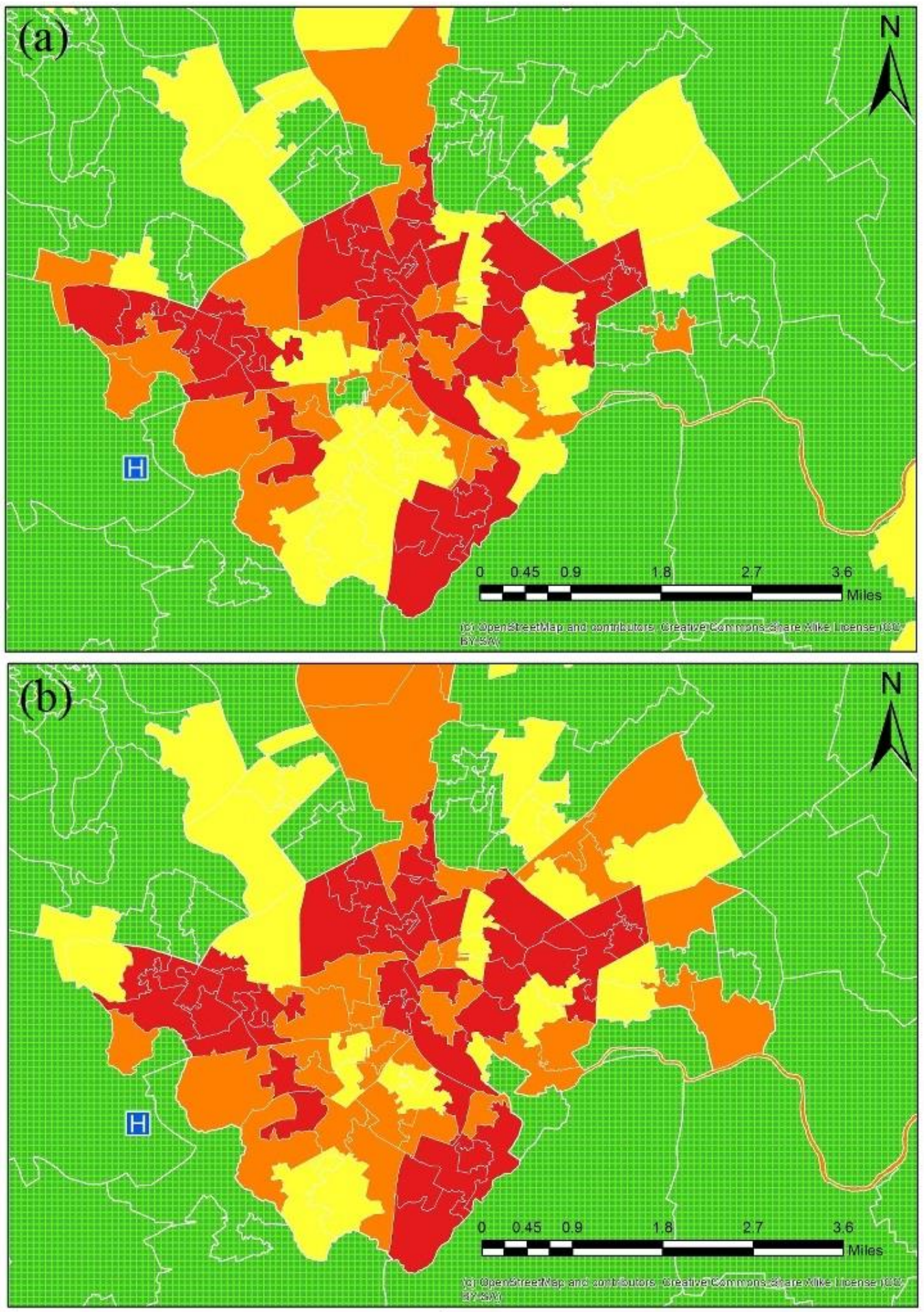

Contains Ordnance Survey data 5 Crown copyright and datahase right 2013, National Statistics data $\$$ Crown copyright and database right 2013; Ordnance Survey data $\approx$ Crown copyright and database right 2013; Census data adapted from data firom the Onlice for National Statistics licensed under the Open

Govermment Licenoe v.1.0; Environment Agency dala Copyright Enviroumen

Agency 2013; OpenStreetMap data: O OpenStreetMap contributors; and

H Hospitals

Vulnerability Ranking

Ordnance Survey OpenData 0 Crown copyright and database right 2013 Low Vulnerability Low-Moderate Vulnerability Moderate-High Vulnerability High Vulnerability

Figure 9. (a) Local OS-VI Norwich City detail and (b) National OS-VI Norwich City detail. 
We see the OS-VI as a complementary tool to the IMD. The OS-VI is more inclusive, taking into account a broader range of economic as well as social indicators that address vulnerability in both urban and rural areas, and provides greater local context than the IMD, highlighting potential vulnerability hotspots and the driving forces or root causes of vulnerability.

\section{Concluding remarks}

There have been few examinations of comparative indicators of social vulnerability that incorporate measures of accessibility and flood risk. Fewer studies still have integrated a broad spectrum of vulnerability indicators available at the national level but with a resolution that allows for the representation of local-level vulnerability. Furthermore, limited attention has been paid to the use of open-source data and technology, with proprietary sources preferred. The approach presented here addresses these limitations.

The index produced draws considerable influence from Blaikie et al.'s (1994) Pressure and Release Model by directing attention to the root causes of social vulnerability within communities but also Cutter et al.'s $(1996,2008)$ hazards of place model by focussing explicitly on place vulnerability within the OS-VI, particularly relative local vulnerability within the Local OS-VI. The inclusion of both vulnerability indicators and a measure of risk potential via the flood hazard zone within the OS-VI provides a comprehensive picture of social vulnerability and allows for the examination of the interaction between socioeconomic and biophysical vulnerabilities.

The goal of this project was to utilise free and readily available secondary data to produce a tool that could be used by local councils or NGOs to identify communities that may require added assistance before, during or after a flood event. The methodological approach presented provides a mechanism whereby quality data on core drivers of vulnerability can be used to create a vulnerability index that provides information at a national level but at a sufficiently fine resolution so as to identify pockets of vulnerable communities. The methods used are scalable and adaptable and the project's reliance on open-source data and technology significantly reduces the associated costs and allows all parties involved to easily coordinate and share information, potentially improving local knowledge and reducing vulnerability (Trujillo, Ordones, \& Hernandes, 2000).

The OS-VI is the first step in imagining a dynamic and customisable platform that can provide added context to complex situations and the targeting of resource and service allocation, be it the provision of programmes to address an identified vulnerability stressor or the location of new facilities to improve accessibility. Future work will focus on further refining the variables and indicators used as well as examining the underlying dimensions of social vulnerability and risk and its changes over space and time. 


\section{Disclosure statement}

No potential conflict of interest was reported by the authors. Funding

This work was supported by the Engineering and Physical Sciences Research Council (EPSRC) under Grant EP/G037698/1 and the British Red Cross (BRC).

\section{ORCID}
K. Garbutt http://orcid.org/0000-0001-9543-2110
C. Ellul http://orcid.org/0000-0002-9791-0259

\section{References}

Aday, L. A. (2001). At risk in America: The health and health care needs of vulnerable populations in the United States. San Francisco, CA: Jossey-Bass.

Adger, W. N. (2006). Vulnerability. Global Environmental Change, 16(3), 268-281. Alexander, D. (1993). Natural disasters. New York, NY: Chapman \& Hall.

Anand, S., \& Sen, A. (1994). Human development index: Methodology and measurement (No. HDOCPA-1994-02). New York, NY: Human Development Report Office (HDRO), United Nations Development Programme (UNDP).

Atteslander, P., Cromm, J., Grabow, B., Klein, H., Maurer, A., \& Siegert, G. (2008). Methoden der empirischen Sozialforschung. Berlin: Walter de Gruyter.

Auf der Heide, E., \& Scanlon, J. (2007). Health and medical preparedness and response. In W. L. Waugh \& K. Tierney (Eds.), Emergency management: Principles and practice for local government (pp. 183-206). Washington, DC: International City Managers Association.

Balica, S., \& Wright, N. G. (2010). Reducing the complexity of the flood vulnerability index. Environmental Hazards, 9(4), 321-339.

Barnett, J., Lambert, S., \& Fry, I. (2008). The hazards of indicators: Insights from the environmental vulnerability index. Annals of the Association of American Geographers, 98(1), 102-119.

Bennet, G. (1970). Bristol floods 1968: Controlled survey of effects on health of local community disaster.

British Medical Journal, 3, 454-458. Bianchi, S. M., \& Spain, D. (1996). Women, work, and family in America. Population Bulletin, 51(3), 1-48. 
Bird, K., \& Prowse, M. (2008). Vulnerability, poverty and coping in Zimbabwe (WIDER Research Paper 2008/41). Helsinki: UNU-WIDER.

Birkmann, J. (2005). Report on the 1st meeting of the expert working group on 'measuring vulnerability’ (Working Paper No. 1). Bonn: United Nations University, UNU EHS.

Blaikie, P., Cannon, T., Davies, I., \& Wisner, B. (1994). At risk: Natural hazards, people's vulnerability and disasters. New York, NY: Routledge.

Bohringer, C., \& Jochem, P. E. P. (2007). Measuring the immeasurable: A survey of sustainability indices. Ecological Economics, 63(1), 1-8.

Brooks, N., Adger, N., \& Kelly, M. (2005). The determinants of vulnerability and adaptive capacity at the national level and the implications for adaptation. Global Environmental Change, 15(2), 151-163.

Bruneau, M., Chang, R. T., Eguchi, G. C., Lee, T. D., O’Rourke, A. M., Reinhorn, M., ... von Winterfeldt, D. (2003). A framework to quantitatively assess and enhance the seismic resilience of communities. Earthquake Spectra, 19(4), 733-752.

Burd-Sharps, S., Lewis, K., \& Martins, E. B., (Eds.). (2008). The measure of America: American human development report, 2008-2009. New York, NY: Columbia University Press.

Cabinet Office. (2013). National risk register of civil emergencies 2013 edition. London: Author.

Campbell, N. C., Elliott, A. M., Sharp, L., Ritchie, L. D., Cassidy, J., \& Little, J. (2000). Rural factors and survival from cancer: Analysis of Scottish cancer registrations. British Journal of Cancer, 82, 1863-1866.

Carroll, A. (2012, May 14). Map shows Norfolk flooding risk zones. Eastern Daily Press.

Chen, A., Keith, V. M., Airriess, C., Li, W., \& Leong, K. J. (2007). Economic vulnerability, discrimination, and Hurricane Katrina: Health among black Katrina survivors in eastern New Orleans. Journal of the American Psychiatric Nurses Association, 13(5), 257-266.

Coffee, N., Turner, D., Clark, R. A., Eckert, K., Coombe, D., Hugo, G., \& Tonkin, A. A. (2012). Measuring national accessibility to cardiac services using geographic information systems. Applied Geography, 34, 445-455.

Comber, A., Brunsdon, C., \& Green, E. (2008). Using a GIS-based network analys is to determine urban greenspace accessibility for different ethnic and religious groups. Landscape and Urban Planning, 86 (1), 103-114.

Cox, J. R., Rosenzweig, C., Solecki, W., Goldberg, R., \& Kinney, P. (2007). Social vulnerability to climate change: A neighborhood analys is of the northeast US Megaregion. Technical paper 
prepared for the Northeast Climate Impacts Assessment, Cambridge, MA.

Cutter, S. (1996). Vulnerability to environmental hazards. Progress in Human Geography, 20(4), 529-539. Cutter, S. (2006, June 11). The geography of social vulnerability: Race, class, and catastrophe. Retrieved from http://understandingkatrina.ssrc.org/Cutter/

Cutter, S., Barnes, L., \& Berry, M. (2008). Community and regional resilience: Perspectives form hazards, disasters and emergency management community and regional resilience initiative (CARRI) (Research Report 1). Oak Ridge: Community and Regional Resilience Institute. Retrieved from http://www. resilientus.org/library/FINALCUTTER9-25-08_1223482309.pdf

Cutter, S., Boruff, B., \& Shirley, W. (2003). Social vulnerability to environmental hazards. Social Science Quarterly, 84(2), 242-261.

Cutter, S., Burton, C. G., \& Emrich, C. T. (2010). Disaster resilience indicators for benchmarking baseline conditions. Journal of Homeland Security and Disaster Resilience, 7(1), 1-22.

Cutter, S. L., \& Emrich, C. T. (2006). Moral hazard, social catastrophe: The changing face of vulnerability along the hurricane coasts. The Annals of the American Academy of Political and Social Science, 604(1), 102-112.

Cutter, S., Emrich, C. T., Webb, J. J., \& Morath, D. (2009). Social vulnerability to climate variability hazards: A review of the literature (Final Report to Oxfam America, 5, 1-44). Columbia: University of South Carolina.

Cutter, S. L., Mitchell, J. T., \& Scott, M. S. (2000). Revealing the vulnerability of people and places: A case study of Georgetown County, South Carolina. Annals of the Association of American Geographers, 90 (4), 713-737.

Damm, M. (2010). Mapping social-ecological vulnerability to flooding. A sub-national approach for Germany (Graduate Research Series vol. 3). Bonn: UNU-EHS.

Delafontaine, M., Neutens, T., \& Weghe, N. (2012). A GIS toolkit for measuring and mapping space - Time accessibility from a place-based perspective. International Journal of Geographical Information Science, 26(6), 1131-1154.

Department for Communities and Local Government. (2011). English indices of deprivation 2010. London: Author. Department for Transport. (2004). Technical guidance on accessibility planning in local transport plans. London: Author.

Department for Transport. (2012). Accessibility statistics 2011. London: Author. DETR. (2000). Measuring multiple deprivation at the small area level: The indices of deprivation 2000. London: Author.

Dibben, C. Atherton, I., Cox, M., Watson, V., Ryan, M., \& Sutton, M. (2004). Investigating the 
impact of changing the weights that underpin the index of multiple deprivation 2004. London: Department for Communities and Local Government.

Dwyer, A., Zoppou, C., Nielsen, O., Day, S., \& Roberts, S. (2004). Quantifying social vulnerability: A methodology for identifying those at risk to natural hazards (Geoscience Australia Record 14, 1-92). Canberra: Geoscience Australia.

Enarson, E. (2007). Identifying and addressing social vulnerabilities. In K. Tierney \& K. Waugh (Eds.), Emergency management: Principles and practice for local government (pp. 257-278). Washington, DC: International City and County Management Association.

Enarson, E., \& Morrow, B. (1998). The gendered terrain of disaster. New York: Praeget. Engle, N. L. (2011). Adaptive capacity and its assessment. Global Environmental Change, 21(2), 647656.

Erskine, S. (2010). Socioeconomic deprivation, urban-rural location and alcohol-related mortality in England and Wales. BMC Public Health, 10(1), 1-99.

Esty, D., Levy, M., Srebotnjak, T., \& de Sherbinin, A. (2005). Environmental sustainability index: Benchmarking national environmental stewardship. New Haven, CT: Yale Center for Environmental Policy and Law. Experian. (2014). MOSAIC classification. Retrieved from http://www.experian.co.uk/marketing-services/products/mosaic-uk.html

Farrington, J., \& Farrington, C. (2005). Rural accessibility, social inclusion and social justice: Towards conceptualisation. Journal of Transport Geography, 13(1), 1-12.

Fekete, A. (2011). Spatial disaster vulnerability and risk assessments: Challenges in their quality and acceptance. Natural Hazards, 61(3), 1161-1178.

Floyd, P., \& Tunstall, S. (Risk and Policy Analysis/Flood Hazard Research Centre). (2004). The appraisal of human-related intangible impacts of flooding (Report to Defra/Environment Agency, R\&D Project FD2005). London: Defra.

Garbutt, K. (2013). Using GIS and an indicator-based approach to identify and map social vulnerability: A case study of Norfolk, England. A thesis presented for the degree of Master of Research at University College London.

Gartner, A. (2011). Rura/urban mortality differences in England and Wales and the effect of deprivation adjustment. Social Science \& Medicine, 72(10), 1685-1694.

Goss, J. (1995). We know who you are and we know where you live: The instrumental rationality of geo- demographic systems. Economic Geography, 71(2), 171-198.

Greater London Authority. (2013, November). Better environment, better health: A GLA guide for London's Boroughs London Borough of Waltham Forest. London: Author. 
Gunderson, L. (2009). Comparing ecological and human community resilience (CARRI Research Report 5). Oak Ridge: Community and Regional Resilience Institute.

Hajat, S., Ebi, K. L., Kovats, R. S., Menne, B., Edwards, S., \& Haines, A. (2005). The human health consequences of flooding in Europe: A review. In Extreme weather events and public health responses (pp. 185-196). Berlin Heidelberg: Springer.

Haki, Z., \& Akyurek, Z. (2004, April 29-May 1). Assessment of social vulnerability using geographic infor- mation systems: Pendik, Istanbul case study. Paper presented at the 7th AGILE conference on Geographic Information Science, Heraklion, Crete.

Halden, D., Jones, P., \& Wixey, S. (2005). Measuring accessibility as experienced by different socially dis- advantaged groups: Accessibility analysis literature review. London: Transit Studies Group, University of Westminster.

Higgs, G. (2004). A literature review of the use of GIS-based measures of access to health care services. Health Services \& Outcomes Research Methodology, 5(2), 119-139.

Hills, J. (2012). Getting the measure of fuel poverty final report of the fuel poverty review. CASE report 72 Commissioned by the UK Government's Department of Energy and Climate Change (DECC).

Jones, P. G., \& Thornton, P. K. (2003). The potential impacts of climate change on maize production in Africa and Latin America in 2055. Global Environmental Change, 13, 51-59.

Kasperson, J. X., \& Kasperson, R. E. (2001). International workshop on vulnerability and global environ- mental change (SEI Risk and Vulnerability Programme Report 2001-01). Stockholm: Stockholm Environment Institute.

Kaźmierczak, A., \& Cavan, G. (2011). Surface water flooding risk to urban communities: Analys is of vulnerability, hazard and exposure. Landscape and Urban Planning, 103(2), 185-197.

Kværner, J., Swensen, G., \& Erikstad, L. (2006). Assessing environmental vulnerability in EIA the content and context of the vulnerability concept in an alternative approach to standard EIA procedure. Environmental Impact Assessment Review, 26(5), 511-527.

Lankao, P. A., \& Qin, H. (2011). Conceptualizing urban vulnerability to global climate and environmental change. Current Opinion in Environmental Sustainability, 3(3), 142-149.

Liu, S., \& Zhu, X. (2004). An integrated GIS approach to accessibility analysis. Transactions in GIS, 8, 45-62. Liverman, D. (1989). Vulnerability to global environmental change. In R. E. Kasperson, K. Dow, D. Golding, \& J. X. Kasperson (Eds.), Understanding global environmental change: The contributions of risk analysis and management (pp. 27-44). Worcester, MA: Clark University, The Earth Transformed Program 1.

Long, A. (2007). Poverty is the new prostitution: Race, poverty, and public housing in post-Katrina New Orleans. Journal of American History, 94, 795-803. 
Lucas, K., Tyler, S., \& Christodoulou, G. (2009). Assessing the 'value' of new transport initiatives in deprived neighbourhoods in the UK. Transport Policy, 16(3), 115-122.

Marmot, M. (2005). Social determinants of health inequalities. The Lancet, 365(9464), 10991104.

Mavoa, S., Witten, K., McCreanor, T., \& O’Sullivan, D. (2012). GIS based destination accessibility via public transit and walking in Auckland, New Zealand. Journal of Transport Geography, 20(1), 15-22.

Meyer, V., Haase, D., \& Scheuer, S. (2007). GIS-based multicriteria analysis as decision support in flood risk management (Integrated project FLOODsite, milestone report). Helmholz Unweltforschungszentrum (UFZ). Department of Economics, Leipzig.

Miller, H. J. (2003). Transportation and communication lifeline disruption. In S. L. Cutter, D. B. Richardson, \& T. Wilbanks (Eds.), The geographic dimensions of terrorism (pp. 145-152). Evanston, IL: Routledge.

Moldan, B., \& Dahl, A. L. (2007). Challenges to sustainability indicators. In T. Hak, B. Moldan, \& A. L. Dahl (Eds.), Sustainability indicators. A scientific assessment (pp. 1-27). Washington, DC: Island Press.

Morath, D. P. (2010). Social vulnerability and public health: Developing a metric for medical emergency management in Florida. A thesis presented for the degree of Master of Science at the University of South Carolina.

Morrow, B. (1999). Identifying and mapping community vulnerability. Disasters, 23(1), 118. Morrow, B. (2008). Community resilience: A social justice perspective (The community and regional resilience initiative research report 4). Oak Ridge, TN: Community and Regional Resilience Initiative.

Morse, S. (2004). Indices and indicators in development: An un-healthy obsession with numbers. Sterling, VA: Earthscan.

Mustafa, D., Ahmed, S., Saroch, E., \& Bell, H. (2011). Pinning down vulnerability: From narratives to numbers. Disasters, 35(1), 62-86.

Musterd, S., \& Ostendorf, W. (2013). Urban segregation and the welfare state: Inequality and exclusion in western cities. New York, NY: Routledge.

Müller, A., Reiter, J., \& Weiland, U. (2011). Assessment of urban vulnerability towards floods using an indicator-based approach - A case study for Santiago de Chile. Natural Hazards and Earth System Science, 11(8), 2107-2123.

Nelson, C., Lurie, N., Wasserman, J., Zakowski, S., \& Leuschner, K. J. (2007). Conceptualizing 
and defining public health emergency preparedness (RAND Working Paper - May 2008). Emmitsburg, MD: National Emergency Training Center.

Nettleton, M., Pass, D. J., Walters, G. W., \& White, R. C. (2007). Public transport accessibility map of access to general practitioners surgeries in Longbridge, Birmingham, UK. Journal of Maps, $2,64-75$.

Neutens, T., Delafontaine, M., Scott, D. M., \& De Maeyer, P. (2012). A GIS-based method to identify spatio-temporal gaps in public service delivery. Applied Geography, 32(2), 253-264.

Nicholl, J., West, J., Goodacre, S., \& Turner, J. (2007). The relationship between distance to hospital and patient mortality in emergencies: An observational study. Emergency Medicine Journal, 24(9), 665-668.

Niemeijer, M. (2002). Developing indicators for environmental policy: Data-driven and theorydriven approaches examined by example. Environmental Science \& Policy, 5, 91-103.

Ngamini Ngui, A., \& Vanasse, A. (2012). Assessing spatial accessibility to mental health facilities in an urban environment. Spatial and Spatio-Temporal Epidemiology, 3(3), 195-203.

Norris, F. H., Stevens, S. P., Pfefferbaum, B., Wyche, K. F., \& Pfefferbaum, R. L. (2008). Community resilience as a metaphor, theory, set of capacities, and strategy for disaster readiness. American Journal of Community Psychology, 41, 127-150.

Office for National Statistics. (2013). Census key statistics. London: Author.

O’Sullivan, C., Mulgan, G., Ali, R., \& Norman, W. (2009). Sinking and swimming: Understanding Britain's unmet needs. London: Young Foundation.

Oxfam America. (2009). Exposed: Social vulnerability and climate change in the US Southeast. Boston, MA: Oxfam.

Oxford Consultants for Social Inclusion. (2012). Getting the measure of rural deprivation in Wales: A report commissioned by the Local Government Data Unit, Wales Office for National Statistics, 2013. Cardiff: Local Government Data Unit.

Páez, A., Scott, D. M., \& Morency, C. (2012). Measuring accessibility: Positive and normative implemen- tations of various accessibility indicators. Journal of Transport Geography, 25, 141153.

Patt, A. G., Tadross, M., Nussbaumer, P., Asante, K., \& Metzger, M. (2010). Estimating leastdeveloped countries' vulnerability to climate-related extreme events over the next 50 years. PNAS, 107(4), 1333-1337.

Peguero, A. A. (2008). The victimization and vulnerabilities of immigrant children: The 
importance of English proficiency. In R. Perrucci, K. Ferraro, J. Miller, \& G. W. Muschert (Eds.), Agenda for social justice: Solutions 2008. Knoxville, TN: Society for the Study of Social Problems.

Polsky, C., Neff, R., \& Yarnal, B. (2007). Building comparable global change vulnerability assessments: The vulnerability scoping diagram. Global Environmental Change, 17, 472-485.

Prescott-Allen, R. (2001). The wellbeing of nations. New York, NY: Island Press. Preston, B. L. (2012). Climate change vulnerability assessment: From conceptual frameworks to practical heuristics (Climate Adaptation Flagship Working Paper). Dickson, CA: CSIRO.

Preston, J., \& Rajé, F. (2007). Accessibility, mobility and transport-related social exclusion. Journal of Transport Geography, 15(3), 151-160.

Reacher, M., McKenzie, K., Lane, C., Nichols, T., Iversen, A., Hepple, P., ... Simpson, J. (2004). Health impacts of flooding in Lewes: A comparison of reported gastrointestinal and other illness and mental health in flooded and non-flooded households. Communicable Disease and Public Health, 7(1), 1-8.

Ribeiro, A., Antunes, A. P., \& Páez, A. (2010). Road accessibility and cohesion in lagging regions: Empirical evidence from Portugal based on spatial econometric models. Journal of Transport, 10, $125-132$.

Rogers, S. (2012, March 6). Poverty in England: How Experian ranks where you live. Guardian. Retrieved from http:/www.theguardian.com/news/datablog/2012/mar/06/poverty-englandexperian-rankings

Rygel, L., O'Sullivan, D., \& Yarnal, B. (2006). A method for constructing a social vulnerability index: An application to hurricane storm surges in a developed country. Mitigation and Adaptation Strategies for Global Change, 11(3), 741-764.

Schneiderbauer, S. (2007). Risk and vulnerability to natural disasters-from broad view to focused perspective: Theoretical background and applied methods for the identification of the most endangered populations in two case studies at different scales. A thesis presented for the degree of Doctor of Philosophy at Freie Universität, Berlin.

Scott, D. M., \& Horner, M. W. (2008). Examining the role of urban form in shaping people's accessibility to opportunities: An exploratory spatial data analysis. Journal of Transport and Land Use, 1(2), 89-119.

Stângă, I. C., \& Grozavu, A. (2012). Quantifying human vulnerability in rural areas: Case study of Tutova Hills (Eastern Romania). Natural Hazards and Earth System Science, 12(6), 1987-2001.

Tapsell, S. M., \& Tunstall, S. M. (2006). The mental health aspects of floods: Evidence from England and Wales. In R. Few \& F. Matties (Eds.), Flood hazards and health: Responding to 
present and future risks (pp. 89-110). London: Earthscan.

Tate, E. (2013). Uncertainty analysis for a social vulnerability index. Annals of the Association of American Geographers, 103(3), 526-543.

Taubenböck, H., Post, J., Roth, A., Zosseder, K., Strunz, G., \& Dech, S. (2008). A conceptual vulnerability and risk framework as outline to identify capabilities of remote sensing. Natural Hazards and Earth System Science, 8(3), 409-420.

Tierney, K. J., Lindell, M. K., \& Perry, R. W. (2001). Facing the unexpected: Disaster preparedness and response in the United States. Washington, DC: Joseph Henry Press.

Trujillo, M., Ordones, A., \& Hernandes, C. (2000). Risk mapping and local capacities: Lessons from Mexico and Central America. Oxford: Oxfam.

Trujillo-Pagan, N. (2007). Katrina's Latinos: Vulnerability and disasters in relief and recovery. In K. A. Bates \& R. S. Swan (Eds.), Through the eye of Katrina: Social justice in the United States (pp. 147-168).

Durham, NC: Carolina Academic Press. Tunstall, S. M., Tapsell, S. M., Green, C., Floyd, P., \& George, C. (2006). The health effects of flooding: Social research results from England and Wales. Journal of Water and Health, 4(3), 365-380.

Turvey, R. (2007). Vulnerability assessment of developing countries: The case of small island developing states. Development Policy Review, 25(2), 243-264.

Van Zandt, S., Peacock, W. G., Henry, D. W., Grover, H., Highfield, W. E., \& Brody, S. D. (2012). Mapping social vulnerability to enhance housing and neighborhood resilience. Housing Policy Debate, 22(1), 29-55.

Vincent, K. (2004). Creating an index of social vulnerability to climate change for Africa (Tyndall Center for Climate Change Research Working Paper 56, p. 41). Norwich: Tyndall Centre for Climate Change Research.

Wamsler, C. (2014). Cities. Disaster risk and adaptation. New York, NY: Routledge.

Watts, M. J., \& Bohle, H. G. (1993). The space of vulnerability: The causal structure of hunger and famine. Progress in Human Geography, 17(1), 43-67.

Webber, D. J., \& Rossouw, S. (2010). Sub-national vulnerability measures: A spatial perspective, Auckland (Economics Discussion Paper Series, 1004). Bristol: Department of Accounting, Economics and Finance, Bristol Business School, University of the West of England.

Whelan, C. T., \& Bertrand, M. (2005). Vulnerability and multiple deprivation perspectives on economic exclusion in Europe: A latent class analysis. European Societies, 7(3), 423-450. 
Wisner, B., Blaikie, P., Cannon, T., \& Davis, I. (2004). At risk: Natural hazards, people's vulnerability and disasters. Oxford: Routledge. World Health Organization. (2002). Floods: Climate change and adaptation strategies for human health (Meeting report). London, 30 June-2 July 2002. Copenhagen: WHO Regional Office for Europe. Retrieved from http:/www.who.dk/document/E77096.pdf

Yoon, D. K. (2012). Assessment of social vulnerability to natural disasters: A comparative study. Natural Hazards, 63(2), 823-843. 